\title{
Detailed Perceptions by Health Service Providers Around EHRs: A Case Study of Australia's e-health Solution
}

\author{
Imran Muhammad \\ Deakin Univesity, Epworth Healthcare \\ Imran.muhammad@deakin.edu.au
}

\author{
Nilmini Wickramasinghe \\ Deakin University, Epworth Healthcare \\ n.wichramasinghe@deakin.edu.au
}

\begin{abstract}
The Australian government has invested heavily in the national e-health solution; namely, initially, the PCEHR, now MyHealth Record. A critical success factor is concerned with the perception and expectations of health service providers regarding the MyHealth Record. Further, it is important to understand the effect of the MyHealth Record on the patient-provider relationship, quality of care, and service providers' views toward data security and confidentiality. The primary goal of this pilot study is to understand the health service providers' perceptions and expectations; and thereby, predict the likely sustainability of the MyHealth Record. This has important implications in general as all OECD countries' transition to large scale e-health solutions.
\end{abstract}

\section{Introduction}

All Healthcare systems, globally, have several challenges in common. These relate to unsustainable increase in cost, uneven quality of care, and even persistent barriers to universal access [1]. These, combined with the increasing population, aging, and new lifestyles, have represented a call of urgent action to policy and decision-makers to start developing alternative options to put the healthcare services industry at the top most probity, which leads to a safe, effective, patient-centered, timely, efficient and equitable healthcare system [2]. These challenges have exposed the fragility of healthcare systems and their infrastructure further; and emphasise, the need to establish a reliable and coherent plan to deal with these challenges [3].

In response to these challenges, e-health initiatives, particularly the Electronic Health Record (EHR) is being embraced and instigated around the globe [4]. Previous reports call for the use of an EHR for better health information sharing and for more efficient healthcare delivery with more successful healthcare outcomes [5]-[8].

Australia, like many other developed countries, is investing heavily in e-health initiatives namely the MyHealth Record. Specifically, in the federal budget for the fiscal year (2014-15) the government allocated an extra Australian \$146.6 million on top of its previous commitment of Australian \$466.7 million to overhaul the healthcare system of Australia. Despite the noteworthy investment, it continues to struggle to implement my MyHealth Record. The implementation of the MyHealth Record has raised many interesting questions concerning service provider's perceptions and expectations of MyHealth Record, further it also raises questions about policy issues - such as patient privacy, security of information, identification and management of patient's consent for participation, and data collection. Technical issues concerning system complexity, user understanding of the system, lack of standards and protocols are also often raised [9]-[13]. These issues are very important to investigate and research to provide data and information that will assist in a smooth and successful MyHealth Record implementation [10], [14]-[16].

Given the inherent complexities of healthcare operations, it has been argued that it is important to understand the requirements of eHealth users' i.e. service providers in this case. In addition, to achieve the successful implementation and adoption of the MyHealth Record it is important to understand the expectations and perceptions of service providers. Thus, this study was conducted to understand the expectations and perceptions of MyHealth Record users (service providers). This study serves to answer the key research question "What impact does service providers' perceptions and expectation of MyHealth Record have on their adaption and use decision?"

There are very few studies in the literature that examine user perceptions and expectations of any kind of EHR or PHR especially focusing on service providers. In the Australian context, there is no study 
to date that has been conducted to examine user expectations and perceptions of MyHealth Record especially relating to service providers. This study has been conducted to fill this important gap.

\section{Background}

In order to understand the perceptions and expectations of health service providers around MyHealth Record, it is first necessary to briefly understand the Australian healthcare delivery system.

\subsection{Structure of Healthcare Delivery in Australia}

The healthcare system in Australia is a combination of private and public-sector care providers, comprising of over 1326 hospitals, which serve around 22.6 million citizens across different geographic and socio-economic settings. Healthcare service delivery and financing is the joint responsibility of federal, state and territory governments through, taxation, Medicare levy and council rates along with some contribution from local governments as well as private health insurance companies and consumers [2], [17].

Public hospitals are managed and operated under the ownership of state and territory governments which provide free service at the point of delivery for all Australian citizens. State and territory governments are also responsible for the delivery of community health, aged-care, mental health, patient transport and dental services for mostly free of cost to Australian consumers.

The Commonwealth Government is responsible for healthcare policy development, healthcare service regulation and healthcare funding through the Australian Health Care Agreements (AHCA) to state and territory governments [2]. In addition, the Commonwealth Government provides rebates to patients through Medicare Australia a "universal (government) health insurance" system and pharmaceutical benefits scheme(ibid). Finally, the Commonwealth Government regulates the private health insurance industry (ibid).

In the Australian context, there are three different levels of healthcare service delivery, namely:

1. Primary Care: A community based first point of interaction between patients and range of healthcare service providers such as GPs, Nurses, family physicians, pharmacist and in some regions clinical officer, Ayurvedic or traditional medicine.

2. Secondary Care: This is a healthcare service provided by specialist doctors such as gynecologists, cardiologists, endocrinologists. In Australia, primary care provider need to give a referral for secondary care provider.

3. Acute Care: This is a specialised healthcare service provided in hospitals for advanced medical diagnoses, investigation and treatments.

The Australian model of healthcare is predominantly hospital-centric and there is a growing concern that these kinds of models are not sustainable in long run. Hospital-centric or acute healthcare service delivery models are complex and costly and need to be reviewed [2], [18], [19]. For example, people with mental health and chronic disease might need lifelong support and care most of which can be provided through self-management or a primary healthcare system, which would be cost-effective and would help to reduce burden from hospitals [20] but more importantly also better suited to the patients' needs.

The transformation from hospital-centric healthcare system to a primary healthcare model has been realised through the Australian healthcare reform and a comprehensive healthcare reform strategy has been introduced in 2010 [19]. Before we take a deeper look into the Australian healthcare reforms it is important to highlight the key issues and challenges driving these reforms.

\subsection{Challenges Faced by the Australian Healthcare System}

Like all OECD countries, the Australian healthcare system is confronting major healthcare funding and delivery challenges. A further challenge relates to the fact that, even though the healthcare system in Australia has been considered highly ranked internationally because of high life expectancy and low infant mortality [17]; this ranking is now under strain as the system is hardpressed by an ageing population, increased prevalence of chronic disease and its burden on healthcare service, and out-dated infrastructure and organisation models of healthcare delivery [17]. In addition, healthcare inequalities also persist in Australia and the gap of service accessibility between rich and poor is widening markedly [2].

A report by Australian Bureau of statistics (ABS) has predicted that by $2020 ; 16 \%$ of Australians would be aged 65 or over and this could rise to $27 \%$ by 2101 because of low fertility rate and increased life expectancy [21]. This can put enormous pressure on healthcare budgets [22], and currently healthcare expenditure is increasing with Australia already spending $9.6 \%$ of their GDP on healthcare and this is expected to rise by $16 \%$ to $20 \%$ if current trends for 
healthcare demands continue [19]. Another devastating effect for Australia, since although it has a two-tier healthcare system the dominant system is the government or national healthcare system, would be a decrease in the working population and shortage of workforce in all areas including healthcare that will lead to reduced tax collection which is a major source of healthcare funding [19], [23].

Increased prevalence of chronic disease is another major issue especially with the increasing ageing population incidence of chronic diseases; an estimated $25 \%$ of the Australian population is suffering from chronic illnesses which is increasing at a very rapid pace [24]. Persistent health inequalities, rapid pace of inventions into new technologies and medicines and consumer expectations are also putting more pressures for increased healthcare spending [25].

One way of handling these issues is to reorient the healthcare system towards prevention rather than cure and community based self-management care systems for chronically ill patients by involving them in their care management process. This would reduce the burden from hospitals and health budgets. For this to be successful it is necessary to have a nationwide health information technology solution which has capacity to decrease health disparities and improve self-management of healthcare [26], healthcare efficiency, quality and safety [27].

Another major issue with the Australian healthcare delivery system is its fragmented nature. The system operates as a disintegrated and disparate set of services. In particular, there is no coordination between primary healthcare service providers and acute healthcare service providers [2]. Thus, there is a greater need of coordination between and across different elements and areas of the healthcare system for fast and cost-effective service delivery and again without a nationwide technology solution this is not possible [19].

Yet another major issue is the inability of collecting and sharing health information of patients among different sectors of healthcare service [2], [17], [23]. The current situation can pose a very serious risk of diagnosis and treatment errors, increase-waiting times for referrals, increase diagnostic test duplications, slow down hospital discharges and can have adverse effects on administration staff work efficiency [17], [23].

It is generally agreed to by the government that doing more of the same is not enough to tackle these issues and challenges and a comprehensive reform of the Australian healthcare system is needed [5], [19], [23].
A report prepared by Deloitte, suggests that the meaningful improvements in any performance can only be achieved if any reform can bring about significant improvements in the way information in the healthcare sector of Australia is collected, used, shared and disseminated [5]. In order to achieve this, a meaningful use of Information Technology(IT) is proposed by many; especially since the current state of Information Communication Technologies(ICT) use in Australian healthcare sector to date has been woefully inadequate [5].

\subsection{Lack of ICT Use in Australian Healthcare Sector}

The Information Age is changing the landscape of information retrieval and information distribution techniques which in return is placing more value on its means [28]. It has been identified by many researchers that one of the fundamental challenges healthcare systems are facing is related to managing and sharing patient records and information and finding cost effective and efficient means to do so [27], [29], [30]. Although medical and diagnostic technologies are at very advance stages and provide help with rapid identification and treatment of illness, the ability to share this information among service providers is nowhere near optimal [31]. While this is true in all OECD countries, to date Australia has been very slow to embrace ICT to facilitate superior healthcare delivery.

The knowledge and use of e-health technologies across different sectors of the Australian healthcare system varies considerably. For instance, the computer penetration in primary care sector is significantly high with $96 \%$ GPs (general practitioners) are using computers for their general practice due to the Australian government interventions and incentives provided to GPs [32]. however, the primary use of computers at work by GPs is for prescription printing (94.7\%), test orders $(82.2 \%)$, and patient information and medical record data storage $(79.5 \%)$ and for some extent sharing data with in the medical facility without having any capability to share this data and information electronically [24], [32].

The penetration level of computer uses in other parts of the health sector such as community pharmacies radiology and pathology is relatively high, with the ability of supporting most of their business and clinical activities, however the ICT implementation and use with in the clinical specialist community, aged care, and allied health is very limited. They use computers for their business purpose but very limited use of clinical information 
storage and exchange electronically, many service providers from this part of the health sector would need to upgrade or install core computing infrastructure along with health management information systems to align their capabilities of meaningful participation and use of e-health initiatives of government [32]. The stories of mixed ICT capabilities also hold true for acute sector of healthcare in Australia because their ICT needs are complex. Some hospitals are using very sophisticated technology while other needs heavy investments for IT infrastructure to reach basic level of capabilities [33].

To address these challenges, Australia has developed an e-health strategy [9], under this strategy the Australian government is implementing a nationwide e-health solution known today as the MyHealth Record

\section{Methodology}

A single case study methodology was adopted for this study. The data were gathered through a survey and, to analyze the collected data, a mixed method approach was adopted including descriptive statistical data analysis techniques and standard qualitative analysis techniques. A survey instrument was developed to collect data to answer the primary research question presented in the introduction section. The survey questions were designed to evaluate the preparedness of key stakeholders of MyHealth record users namely service providers to adapt and use the system. To check the reliability and validity of the survey instrument we ran a pilot study on a small group of the population from diverse demographic background. All necessary, ethics approvals were secured before data collection commenced.

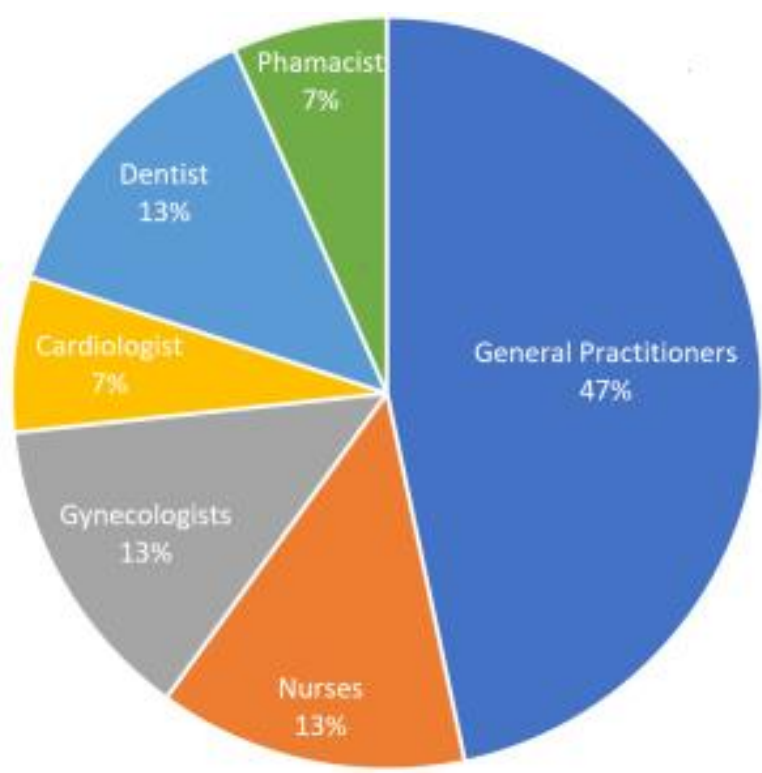

Figure 1: Distribution of Survey Respondents

\subsection{Service Provider survey questionnaires}

A Pilot survey questionnaire was administered to healthcare service providers (general practitioners (GPs), Nurses, Acute healthcare providers, specialist doctors). A group of selected healthcare service providers who are eligible for Health Identifiers were asked to participate. This survey was published online through Qualtrics. The response rate was very low with just 5 responses received online. The researcher also distributed printed surveys and the response was low with 10 completed surveys received. Table 1 shows the distribution of survey respondents.

\section{Data Analysis and Discussion}

This section discusses the results of the pilot survey of healthcare service providers.

\subsection{Use of Computer and HIT in Medical Practitioners Practices}

Providers were asked about the use of computers within their healthcare practices and the knowledge to use the computers effectively. All providers responded affirmatively to both questions. Most of the providers, $83 \%$ indicated that computer experience and training was primarily self-guided, while $17 \%$ indicated that training occurred during graduate studies. When asked about how comfortable a provider was using a computer, $50 \%$ indicated being a general user that was well-rounded and 
knowledgeable, while the other $50 \%$ indicated being advanced users with the ability to assist others, and work independently. Use of an Internet or computer based HIT systems for healthcare delivery by providers was $83 \%$, leaving approximately $17 \%$ not using any HIT system. Perceptions from providers for using the Internet or HIT systems were mostly positive, especially for medical billings, appointments, and searching for descriptions of diseases. Table 1 depicts the results of HIT use.

\begin{tabular}{|c|c|c|}
\hline$\#$ & Purpose of use & $\begin{array}{l}\text { \% of } \\
\text { Use }\end{array}$ \\
\hline 1 & Medical billing or payment & $80 \%$ \\
\hline 2 & Fill a prescription & $40 \%$ \\
\hline 3 & Make an appointment with patient & $80 \%$ \\
\hline 4 & Communicate with patient & $20 \%$ \\
\hline 5 & $\begin{array}{l}\text { Search for health relating } \\
\text { information }\end{array}$ & $100 \%$ \\
\hline 6 & $\begin{array}{l}\text { Record patient's symptoms and } \\
\text { health information }\end{array}$ & $80 \%$ \\
\hline 7 & $\begin{array}{l}\text { Record activities track health } \\
\text { progress of the patient }\end{array}$ & $73 \%$ \\
\hline 8 & $\begin{array}{l}\text { Disease information and terms } \\
\text { used in treatment }\end{array}$ & $100 \%$ \\
\hline 9 & $\begin{array}{l}\text { Disease specific or general health } \\
\text { related chat rooms }\end{array}$ & $0 \%$ \\
\hline 10 & On-line seminars & $40 \%$ \\
\hline 11 & $\begin{array}{l}\text { find a hospital or specialist that } \\
\text { treat a specific disease }\end{array}$ & $20 \%$ \\
\hline
\end{tabular}

Current HIT systems used within the health service providers facilities varied widely in the ability to generate reports with specific information. For facilities generating list of patients by diagnosis or health risk were mixed results $50 \%$ indicated it was easy for them where is $33 \%$ did not have facility and $17 \%$ felt it is very difficult task. On the other hand, $66 \%$ facilities could generate list of patients by library test easily. The reporting capabilities were dependent upon the capabilities within the HIT system and the abilities of the providers or staff. Perceptions of the reporting capabilities of the HIT system were mixed.

\subsection{Barriers of Using HIT in Healthcare Service Provider Practice}

To understand the intentions of service providers to use HIT in their practices, the researcher investigated the barriers believed to be significant in terms of HIT use and expending in their practice. The results about barriers to the use of HIT revealed very interesting findings. Service providers consider legislative and legal issues as major barriers and $100 \%$ of respondents were agreed that it is a major barrier. $100 \%$ of respondents were agreed that healthcare delivery settings are complex and this complexity is a major barrier. $83 \%$ consider a lack of sustainable healthcare models a major barrier too. The most interesting results were that $34 \%$ of service providers think privacy and security is not a barrier in HIT implementation and use. The results of their responses are presented in Table 2.

\begin{tabular}{|l|c|c|c|}
\hline \multicolumn{3}{|c|}{ Table 2. Distribution of Survey Respondents } \\
\hline \multicolumn{1}{|c|}{ Barriers } & $\begin{array}{c}\text { Not } \\
\text { Barrier }\end{array}$ & $\begin{array}{c}\text { Minor } \\
\text { Barrier }\end{array}$ & $\begin{array}{c}\text { Major } \\
\text { Barrier }\end{array}$ \\
\hline Staff support & $17 \%$ & $68 \%$ & $15 \%$ \\
\hline Technical support & $0 \%$ & $50 \%$ & $50 \%$ \\
\hline $\begin{array}{l}\text { Knowledge about } \\
\text { system }\end{array}$ & $17 \%$ & $58 \%$ & $25 \%$ \\
\hline Start-up cost & $0 \%$ & $67 \%$ & $33 \%$ \\
\hline Operating cost & $0 \%$ & $35 \%$ & $65 \%$ \\
\hline $\begin{array}{l}\text { Training and } \\
\text { productivity loss }\end{array}$ & $0 \%$ & $83 \%$ & $17 \%$ \\
\hline $\begin{array}{l}\text { Physician } \\
\text { skepticism }\end{array}$ & $0 \%$ & $83 \%$ & $17 \%$ \\
\hline $\begin{array}{l}\text { Privacy or security } \\
\text { concerns }\end{array}$ & $34 \%$ & $49 \%$ & $17 \%$ \\
\hline Lack of standards & $0 \%$ & $34 \%$ & $66 \%$ \\
\hline $\begin{array}{l}\text { Technical } \\
\text { limitations of } \\
\text { systems }\end{array}$ & $0 \%$ & $34 \%$ & $66 \%$ \\
\hline $\begin{array}{l}\text { Lack of } \\
\text { infrastructure }\end{array}$ & $0 \%$ & $50 \%$ & $50 \%$ \\
\hline $\begin{array}{l}\text { Resistance to } \\
\text { change }\end{array}$ & $0 \%$ & $34 \%$ & $66 \%$ \\
\hline Belief and attitude & $0 \%$ & $66 \%$ & $34 \%$ \\
\hline $\begin{array}{l}\text { Lack of } \\
\text { sustainable } \\
\text { models }\end{array}$ & $0 \%$ & $17 \%$ & $83 \%$ \\
\hline $\begin{array}{l}\text { Organizational } \\
\text { culture }\end{array}$ & $0 \%$ & $66 \%$ & $34 \%$ \\
\hline Clarification of & $0 \%$ & $50 \%$ & $50 \%$ \\
\hline
\end{tabular}




\begin{tabular}{|l|c|c|c|}
\hline roles & & & \\
\hline $\begin{array}{l}\text { scare of decrease } \\
\text { in productivity }\end{array}$ & $17 \%$ & $34 \%$ & $49 \%$ \\
\hline Poor governance & $0 \%$ & $83 \%$ & $17 \%$ \\
\hline Leadership & $0 \%$ & $34 \%$ & $66 \%$ \\
\hline Trust & $0 \%$ & $66 \%$ & $34 \%$ \\
\hline $\begin{array}{l}\text { Complex nature of } \\
\text { healthcare settings }\end{array}$ & $0 \%$ & $0 \%$ & $100 \%$ \\
\hline $\begin{array}{l}\text { Stakeholder } \\
\text { support }\end{array}$ & $52 \%$ & $20 \%$ & $28 \%$ \\
\hline $\begin{array}{l}\text { Legislative and } \\
\text { legal issues }\end{array}$ & $0 \%$ & $0 \%$ & $100 \%$ \\
\hline
\end{tabular}

3.3. Service Provider's Expectations of Management Support and Leadership during the MyHealth Record Implementation and Adoption

Top management support and leadership are considered critical success factors for any IT based implementation and adoption. Provider's perception of the role of management in implementing MyHealth record varied widely. More than half of the respondents, $60 \%$, were unsure if MyHealth record was a top priority for management, while $40 \%$ felt that it was a top priority. Providers had an expectation that management would effectively introduce MyHealth record $45 \%$ of the time, leaving most of providers, $55 \%$, believing that management would not introduce the system effectively. Very few providers, $10 \%$, did not feel that consultation or involvement during the implementation process of MyHealth Record was important. Although $90 \%$ of providers wanted to be involved in the process, only $30 \%$ felt that management would involve the providers in the implementation process. Most provider's responses indicated that training was important but only $20 \%$ thought that management would provide the necessary training. Access to the resources needed for effective implementation of MyHealth Record was a concern for providers, 35\% indicated access to resources, $20 \%$ were unsure, and $45 \%$ indicated that appropriate resources to learn and use MyHealth Record would be available.

\subsection{Service Provider's Intentions to Adopt the MyHealth Record}

To understand the intentions of service providers regarding the MyHealth Record adoption, several questions were asked. The responses from these questions helped the researcher to understand the key factors for the MyHealth Record adoption and implementation. The first question the participants were asked was about knowledge and awareness of the MyHealth Record. Most respondents were aware of the MyHealth Record. 21\% strongly disagreed that of being aware of any new e-health system, 17\% neither agreed nor disagreed, whereas $62 \%$ responded were aware of the upcoming MyHealth Record and had a good understanding of the system. When the participants were asked if they see themselves adopting the MyHealth Record early after its roll-out, again results were mixed. Although most the providers indicated early adoption of MyHealth Record, several factors influenced provider intentions. The important factors of the adoption decision process were financial cost, proper training, and the alignment between system values and user values. The providers also indicated that systematic consultation with the user at all levels of the life cycle of the system development and implementation was another consideration. It is important to note that a significant number of respondents indicated that she/he was not the part of the consultation about the MyHealth Record implementation procedures and policies. Most the participants responded that recommendations were not heard or implemented. Respondents indicated several additional factors influencing the decision to implement MyHealth Record. Complexity of the system and time consumption were reported as important factors by $80 \%$ of the respondents, $98 \%$ were in favor of user incentives such as government compensation for start-up, and $76 \%$ were influenced by continuing technical support.

Respondent's perceptions of MyHealth Record largely determines the effectiveness of the system. The large majority of providers, $90 \%$, indicated that Internet based eHealth systems are easy to use. Perceptions of $70 \%$ of the providers indicated that a system that can hold patient records, prepare for patient appointments, prepare online referrals, and access medication information will be useful in providing efficient and effective healthcare services. When asked an opinion about a system that includes a summary of all medical treatment and medication information and is accessible from any location at any time, $81 \%$ of providers would support the adoption of the system. All respondents indicated a willingness to encourage other providers to adopt the system. The decision to adopt a system will be based on the level of security and privacy and ability to integrate with clinical systems for $75 \%$ of the respondents.

\subsection{Intentions to use the MyHealth Record}


The intentions to use a system can predict the likely success of the system [34]. To understand the healthcare service provider's intention to use the MyHealth Record, we asked them 17 questions around the intension of system use. First question sought an opinion about the usefulness of the summary of patient health records available online anywhere, anytime. All respondents indicated that the system would be useful to assist in better provisioning healthcare services. Also, all respondents were in favor of using MyHealth Record if the system provided complete records comparable to current clinical records.

The respondents were asked an opinion about the usefulness of the MyHealth Record in clinical settings. Most respondents, $76 \%$ strongly agreed that the system would improve the quality of service and produce improved healthcare in a clinical setting, while 34\% agreed. Respondents were asked if the MyHealth Record would provide greater control over work schedules which resulted in $49 \%$ indicated being unsure, $17 \%$ agreed, and $34 \%$ strongly agreed. The consensus among service providers was that the MyHealth Record will make their job more efficient, effective and secure.

Although $85 \%$ of the providers indicated that training will be needed, $83 \%$ indicated that adequate training would not be provided.

\subsection{Physician Autonomy}

Physician autonomy, the freedom to treat patients per best judgement, has been a significant part of physician's professional identity [35]. Research has shown that autonomy has been challenged through IT based healthcare interventions (Yarbrough and Smith 2007). E-health is considered one of the challengers in this respect, thus it was important to ask providers about the MyHealth Record and if the MyHealth Record poses any threat to clinical autonomy. Overall, providers disagreed that the MyHealth Record threatened or limited autonomy.

\subsection{Doctor Patient Relation}

The current healthcare model stresses the importance of the key relationship between the service provider and patient. The perception is that $\mathrm{e}$ health can have serious impact on doctor patient relationships by minimizing the interaction between doctors and patients. Investigations to understand the service provider's perceptions about if the MyHealth Record can have any positive or negative impact on this relationship was undertaken. The participants were asked for their opinion about how patients will respond to use of the MyHealth Record instead of personal interactions. All providers indicated that interactions with the MyHealth Record will not reduce patient confidence levels. 83\% strongly agreed and $17 \%$ agreed. Similar response rates were reported when providers were asked about whether the use of MyHealth Record would threaten the credibility of the provider, $83 \%$ strongly disagreed and $17 \%$ disagreed. Providers reported the same feelings about whether it was likely that patient satisfaction with the quality of care will be reduced using MyHealth Record, 83\% strongly disagreed and $17 \%$ disagreed. Participant's responses were slightly different when asked about improvement in the interaction between the provider and patient, $49 \%$ strongly disagreed and 17\% agreed. The results indicate that the general perception of the service provider was positive about MyHealth Record.

\subsection{Physician Leadership}

Physician leadership was another important factor identified during data collection. When service providers were asked if peer groups have established the consensus about the MyHealth Record adoption and use, the majority (54\%) responded that there is no consensus. When asked why there is no consensus, responses indicated that very little is known about MyHealth Record which has created confusion among providers.

Service providers also think that giving consumer's autonomy of their healthcare record is not a good idea and can have negative impact on health service provision. Physicians think that medical terms are difficult to understand for most individuals and can confuse patients. Furthermore, management of a health record will allow a patient to edit or hide information from providers, resulting in a significant obstacle in making informed decisions about patient treatment.

\section{Discussion and Conclusion}

The results of this pilot study revealed that implementation of the MyHealth Record is a complex process becoming more challenging due to increased barriers that need to be overcome. The Australian Government has been enthusiastic about the MyHealth Record's potential benefits with continuous budget investment despite the lower than expected acceptance of the MyHealth Record during the first year. It is understood that the full potential benefits will not be obvious immediately and may 
take many years to realize the impact of the MyHealth Record. Meticulous planning has been completed in the implementation of the MyHealth Record in the system's conceptual, legal, healthcare provider's incentive and training. Different concerns have been raised by service providers as indicated in the analysis.

The results of the data collection and analysis are the plan of a "satisficing" process which includes understanding the need for change and extends beyond the clinical environment to understand the strategic plans, workflows, interactions between human and non-human actors. The results were presented based on service provider's perceptions and expectations from the MyHealth Record collected through survey questionnaires. The results have identified critical factors for the implementation and adoption of MyHealth Record through the lens of socio-technical system perspective [11].

The results of this research indicate that most users of the system (service providers) held positive perceptions that the system can improve patient care and help service providers by providing readily available information to improve decision making and the quality of healthcare services. Even though users were mainly positive about the system, many expressed concerns about legal, privacy, and security issues. Service providers showed more resilience around physician autonomy and doctor patient relations when using MyHealth Record. On the other hand, their perceptions regarding MyHealth Record were positive in terms of use and adoption, but concerns were expressed about the security of information and privacy. Another primary concern was lack of knowledge about MyHealth Record and uncertainty regarding availability.

This study also contributes to literature by highlighting the importance of the use of sociotechnical theories for the analysis of the data gathered for MyHealth Record implementation and use evaluation. The use of Sociotechnical system perspective (STS) to study the healthcare IT implementation and adoption issues is contribution to the theory. In closing, the researcher contends that understanding the key facilitators and barriers to the implementation and adoption of the MyHealth Record in Australia is very important to the success of the system. The real-time collection of health information followed by distribution and access is only possible if widespread adoption of the MyHealth Record is achieved. Seamless sharing of health data between clinical professionals and staff is critical to accommodate the complexity of high risk decisions that must be made based upon available information. The MyHealth Record will only succeed if the government properly supports the reform agenda, directly involves key stakeholders, and understands the perceptions and expectations of professionals and the public. It is evident that the numerous planned eHealth solutions either fail to deliver on promises [11] or wind up closing operations due to the failure of realizing the complexities of healthcare information system implementations.

This study has also contributed to practice by identifying key constraints to MyHealth Record implementation and adoption. The results of this study can be used for other health IT implementations and adoptions, thereby paving the way for improvements to the implementation process of health IT systems which improve to quality and safety of health outcomes for patients and provides benefits to efficiency and effectiveness in the management and provision of healthcare services.

In the context of Australia's MyHealth Record, this research supports the argument of [11] that the implementation and adoption of the MyHealth Record requires a realistic assessment of the e-health environment in Australia and a very clear governance policy, a committed leadership, and sustainable ehealth implementation plan. Furthermore, a suitable IT governance structure is required in primary and acute healthcare facilities to better manage the MyHealth Record implementation and adoption. The concerns identified were two-fold. One; perhaps there hasn't been enough appreciation. First, the Australian government hasn't shown an appreciation of the scale of the MyHealth Record project. This has resulted in the primary focus being placed upon what is going to be at the core of the project; whereas the focus needs to include the various challenges on the periphery.

The MyHealth Record is complimentary to the core of e-health reforms in Australia. To get the best outcomes from an investment in an HIT system, the Government needs to start with a very clear intention of desired business outcomes. Second, the focus is on the technology but requires attention to critical implementation factors such as change, adoption, and engagement with the public and clinicians. Understanding work habits and cultural perspectives will be crucial factors for success of MyHealth Record. If the Government is going to invest billions of dollars in a time when budgets are limited, supporters must be very confident that the system is designed to achieve the desired benefits when MyHealth Record is fully implemented and adopted.

Like all research studies, this study too has limitations. Since the MyHealth Record is part of the Australian National eHealth reform, the data collected did not fully represent all parts of Australia. A review of a limited number of opinions and 
experiences of specific individuals has led to an indepth understanding of specific settings and situations studied at specific sites. The data has provided rich information and insights relating to the case study of the MyHealth Record, however the lack of representation from states like Tasmania and the Northern Territory means caution must be exercised in making generalisations. The next step for successful implementation and adoption of the MyHealth Record and its evaluation is to carry out a larger study for more investigation to examine in greater detail the specific barriers and facilitators identified by this pilot study in a longitudinal study. Multiple case studies carried out in different states of Australia in different setting including primary and acute healthcare settings in various hospitals is another key next step to further improve the generalizability of the findings. Given the growing significance of eHealth implementations and adoptions occurring globally to improve healthcare delivery, successful implementation and adoption of MyHealth Record warrants further study in this important area as well as a comparison between implementations in other countries.

Overall this research serves to demonstrate the importance of e-health implementations in healthcare services and delivery settings of Australia by evaluating the case study of the MyHealth Record. It further identifies the key success factors for the successful implementation and adoption of the MyHealth Record by examining the key user's perspectives of MyHealth Record. This research also notes that a socio-technical analysis techniques need to be used for the analysis of those systems where human and non-human (technology) actors are involved. In summary, it is recommended that more longitudinal research is needed in this growing area of e-health implementation and adoption studies.

\section{References}

[1] N. M. Lorenzi, A. Kouroubali, D. E. Detmer, and M. Bloomrosen, "How to successfully select and implement electronic health records (EHR) in small ambulatory practice settings.," BMC Med. Inform. Decis. Mak., vol. 9, p. 15 , Feb. 2009.

[2] S. Duckett and S. Willcox, The Australian Health Care System, 4th Revised edition. Oxford University Press, 2011.

[3] P. C. Tang, J. S. Ash, D. W. Bates, J. M. Overhage, and D. Z. Sands, "Personal health records: definitions, benefits, and strategies for overcoming barriers to adoption," J. Am. Med. Inform. Assoc., vol. 13, no. 2, p. 121, 2006.
[4] N. Wickramasinghe and J. L. Schaffer, "Creating knowledge-driven healthcare processes with the Intelligence Continuum.," Int. J. Electron. Healthc., vol. 2, no. 2, pp. 164-74, 2006.

[5] Deloitte, "National E-Health Strategy." Australian Government Department of Health and Ageing, 12-Dec2008.

[6] K. Fiscella and H. J. Geiger, "Health information technology and quality improvement for community health centers," Health Aff. Proj. Hope, vol. 25, no. 2, pp. 405412, Apr. 2006.

[7] N. Gill, The impact of e-Health adoption and investment on health outcomes: A study using secondary analysis. University of Toronto, 2010.

[8] A, "NHHRC, "Future for All Australians: National Health and Hospitals Reform Commission-Final Report June .," Aust. Gov. Dep. Health Ageing 27Jul, 2009.

[9] ADoHA and NEHTA, "Concept of Operations: Relating to the introduction of a Personally Controlled Electronic Health Record System,” Article, Sep. 2011.

[10] L. S. Liu, P. C. Shih, and G. R. Hayes, "Barriers to the Adoption and Use of Personal Health Record Systems," Analysis, pp. 363-370, 2011.

[11] I. Muhammad, N. Wickramasinghe, and M. Zwicker, "Using ANT to Understand Key Issues for Successful eHealth Solutions," in Proceedings of the [46th] Annual Hawaii International Conference on System Sciences, Manoa, Hawaii, 2013.

[12] I. Muhammad, S. Y. Teoh, and N. Wickramasinghe, "Why Using Actor Network Theory (ANT) Can Help to Understand the Personally Controlled Electronic Health Record (PCEHR) in Australia," IGI Glob., vol. 4, no. 2, pp. 44-60, 2012.

[13] C. M. Showell, "Citizens, patients and policy: a challenge for Australia's national electronic health record," Health Inf. Manag. J. OnLine, vol. 40, no. 2, 2011.

[14] M. L. Bernstein, T. McCreless, and M. J. Côté, "Five constants of information technology adoption in healthcare.," Hosp. Top., vol. 85, no. 1, pp. 17-25, Winter 2007.

[15] P. C. Tang et al., "Online disease management of diabetes: Engaging and Motivating Patients Online With Enhanced Resources-Diabetes (EMPOWER-D), a randomized controlled trial," J. Am. Med. Inform. Assoc., vol. 20, no. 3, pp. 526-534, May 2013.

[16] M. C. Trudel, "Challenges to personal information sharing in interorganizational settings: Learning from the Quebec Health Smart Card project," THE UNIVERSITY OF WESTERN ONTARIO, 2010.

[17] L. Heslop, Patient and health care delivery systems in the US, Canada and Australia: A critical ethnographic analysis. LAP LAMBERT Academic Publishing, 2010. 
[18] L. Rhyne, "An explorative case study of the transition to the Electronic Clinical Record in the South Australian acute healthcare context: a diffusion of innovation perspective.," Citeseer, 2008.

[19] DoHA, "Building a 21st Century - Primary Health Care System - Australia's First National Primary Health Care Strategy," Australian Government Department of Health and Ageing, May 2010.

[20] E. Willis, L. Reynolds, and K. Helen, Understanding the Australian Health Care System. Elsevier Australia, 2009.

[21] ABS, "Main Features - Key Figures." [Online]. Available:

http://www.abs.gov.au/ausstats/abs@.nsf/mf/3101.0.

[Accessed: 26-Jul-2011].

[22] WHO, The European health report 2009: health and health systems. WHO Regional Office Europe, 2010.

[23] T. Jones, Developing an E-Health Strategy: A Commonwealth Workbook of Methodologies, Content and Models. Commonwealth Secretariat, 2011.

[24] AIHW, Australia's health 2010: the twelfth biennial health report of the Australian Institute of Health and Welfare. The Institute, 2010.

[25] Productivity Commission, Impacts of Advances in Medical Technology in Australia. Productivity Commission, 2005.

[26] A. E. Shields et al., "Adoption of health information technology in community health centers: results of a national survey," Health Aff. (Millwood), vol. 26, no. 5, p. 1373, 2007.

[27] G. R. Wise and R. Bankowitz, "Keys to engaging clinicians in clinical IT," Healthc. Financ. Manag. J. Healthc. Financ. Manag. Assoc., vol. 63, no. 3, pp. 66-70, 72, Mar. 2009.

[28] G. M. Schwarz and D. M. Brock, "WAVING HELLO OR WAVING GOOD-BYE? ORGANIZATIONAL CHANGE IN THE INFORMATION AGE," Int. J. Organ. Anal., vol. 6, no. 1, pp. 65-90, 1998.

[29] J. Aarts and R. Koppel, "Implementation of computerized physician order entry in seven countries.," Health Aff. Proj. Hope, vol. 28, no. 2, pp. 404-14, Apr. 2009.

[30] D. W. Bates, P. C. Tang, J. S. Ash, J. M. Overhage, and D. Z. Sands, "Personal health records: definitions, benefits, and strategies for overcoming barriers to adoption," J. Am. Med. Inform. Assoc. JAMIA, vol. 13, no. 2, pp. 121-126, Apr. 2006.

[31] Westbrook et al., "Use of information and communication technologies to support effective work practice innovation in the health sector: a multi-site study," BMC Health Serv. Res., vol. 9, no. 1, p. 201, 2009.

[32] P. Budde, "Australia's E-Health, E-Education \& EGovernment,” Apr. 2011.
[33] C. Pearce and M. C. Haikerwal, "E-health in Australia: time to plunge into the 21 st century," Med. J. Aust., vol. 193, no. 7, pp. 397-398, Oct. 2010.

[34] V. Venkatesh and S. Goyal, "Expectation disconfirmation and technology adoption: polynomial modeling and response surface analysis," Manag. Inf. Syst. Q., vol. 34, no. 2, p. 6, 2010.

[35] A. K. Yarbrough and T. B. Smith, "Technology acceptance among physicians," Med. Care Res. Rev., vol. 64, no. 6, p. 650, 2007. 